\title{
Dedicated Cold Snare vs. Traditional Snare for Polypectomy of Diminutive and Small Lesions in a Porcine Model: A Research Group for Endoscopic Instruments and Stents (REIS) Study
}

\author{
Han Hee Lee ${ }^{1,2,3}$, Bo-In Lee ${ }^{1,2}$, Jung-Wook Kim ${ }^{4}$, Hyun Lim ${ }^{5}$, Si Hyung Lee ${ }^{6}$, Jun-Hyung Cho ${ }^{7}$, Yunho Jung ${ }^{8}$, Kyoung Oh Kim ${ }^{9}$, Chan \\ Gyoo Kim ${ }^{10}$, Kee Myung Lee ${ }^{11}$, Jong-Jae Park ${ }^{12}$, Myung-Gyu Choi ${ }^{1,2}$, Hoon Jai Chun ${ }^{13}$ and Ho Gak Kim ${ }^{14}$ \\ ${ }^{1}$ Department of Internal Medicine, College of Medicine, The Catholic University of Korea, Seoul, ${ }^{2}$ Catholic Photomedicine Research \\ Institute, Seoul, ${ }^{3}$ Cancer Research Institute, College of Medicine, The Catholic University of Korea, Seoul, ${ }^{4}$ Department of Internal \\ Medicine, Kyung Hee University School of Medicine of Korea, Seoul, ${ }^{5}$ Department of Internal Medicine, Hallym University Sacred \\ Heart Hospital, Anyang, ${ }^{6}$ Department of Internal Medicine, Yeungnam University College of Medicine, Daegu, ${ }^{7}$ Department of Internal \\ Medicine, Soonchunhyang University College of Medicine, Seoul, ${ }^{8}$ Department of Internal Medicine, Soonchunhyang University \\ College of Medicine, Cheonan, ${ }^{9}$ Department of Internal Medicine, Gil Medical Center, Gachon University, Incheon, ${ }^{10}$ Center for Gastric \\ Cancer, National Cancer Center, Goyang, ${ }^{11}$ Department of Internal Medicine, Ajou University School of Medicine, Suwon, ${ }^{12}$ Department \\ of Internal Medicine, Korea University College of Medicine, Seoul, ${ }^{13}$ Department of Internal Medicine, Institute of Gastrointestinal \\ Medical Instrument Research, Korea University College of Medicine, Seoul, ${ }^{14}$ Department of Internal Medicine, Catholic University of \\ Daegu School of Medicine, Daegu, Korea
}

Background/Aims: The aim of this in vivo animal study was to evaluate the effectiveness and safety of dedicated cold snare (DCS) compared with those of traditional snare (TS) for cold snare polypectomy (CSP).

Methods: A total of 36 diminutive $(5 \mathrm{~mm})$ and 36 small $(9 \mathrm{~mm})$ pseudolesions were made by electrocoagulation in the colons of mini-pigs.

Results: For the diminutive lesions, there were no significant differences in technical success rate, procedure time, or complete resection rate between the DCS and TS groups; the rate of uneven resection margin in the DCS group was significantly lower than that of the TS group. For small lesions, technical success rate and complete resection rate were significantly higher in the DCS group than in the TS group (100\% [18/18] vs. $55.6 \%$ [10/18], $p=0.003 ; 94.4 \%$ [17/18] vs. $40 \%[4 / 10], p=0.006)$. In addition, the procedure duration was significantly shorter, and the rate of uneven resection margin was significantly lower in the DCS group ( $28.5 \mathrm{sec}$ vs. 66.0 sec, $p=0.006 ; 11.1 \%[2 / 18]$ vs. $100 \%$ [10/10], $p<0.001$ ). Two cases of perforation occurred in the DCS group. Multivariate analysis revealed that DCS use was independently associated with complete resection.

Conclusions: DCS is superior to TS in terms of technical success, complete resection, and reducing the duration of the procedure for CSP of small polyps. Clin Endosc 2021;54:390-396

Key Words: Animal model; Cold snare polypectomy; Colonic polyps; Dedicated cold snare; Perforation

Received: April 13, 2020 Revised: June 19,2020

Accepted: July 6, 2020

Correspondence: Bo-In Lee

Division of Gastroenterology, Department of Internal Medicine, Seoul St. Mary's Hospital, College of Medicine, The Catholic University of Korea, 222 Banpo-daero, Seocho-gu, Seoul 06591, Korea

Tel: +82-2-2258-2044, Fax: +82-2-2258-2089, E-mail: gidoc4u@gmail.com ORCID: https://orcid.org/0000-0002-0218-4136

(c) This is an Open Access article distributed under the terms of the Creative Commons Attribution Non-Commercial License (http://creativecommons.org/ licenses/by-nc/3.0) which permits unrestricted non-commercial use, distribution, and reproduction in any medium, provided the original work is properly cited.

\section{INTRODUCTION}

Cold snare polypectomy (CSP), which was first introduced in 1992, is used to remove colonic polyps by the transection of the polyp base along with a $2-3-\mathrm{mm}$ cuff of normal mucosa to achieve complete resection. ${ }^{1}$ Since this technique avoids the use of electrocautery, it is theoretically free from the risk of deep thermal injury causing delayed bleeding or perforation.

CSP is proven to have many strengths in terms of efficacy and safety over other polypectomy techniques. For diminutive colon polyps, two prospective randomized studies comparing 
two methods showed that when the polyp size was $4 \mathrm{~mm}$ or more, the rate of complete resection was significantly higher when performing CSP, compared with cold forceps polypectomy. ${ }^{2,3}$ For small colon polyps, CSP had a similar complete resection rate and less delayed bleeding, compared with hot snare polypectomy (HSP). ${ }^{4}$ In addition, CSP was superior to HSP in terms of ease of procedure, and the time required for resection. ${ }^{5}$ The European Society of Gastrointestinal Endoscopy guidelines recommend that if the shape of the superficial colorectal neoplasia is sessile or flat, and the size is diminutive or small, CSP is the best choice to achieve en bloc resection. ${ }^{6}$

To improve the efficacy of CSP, a new device dedicated to performing cold resection was developed; this new device has a shield-shaped loop with a thinner wire. ${ }^{7}$ These properties result in more cutting than tearing through the ensnared mucosa during cold resection, which achieves the resection more easily. ${ }^{8}$ In studies of human colorectal polyps, the superiority of dedicated cold snares (DCSs) has been proven. For a 3-7 $\mathrm{mm}$ polyp, the endoscopic complete resection rate was significantly higher in DCS than the traditional snare (TS) technique. ${ }^{9}$ Another study comparing the two types of snares for polyps up to $10 \mathrm{~mm}$ in diameter showed that the histological complete resection rate was significantly higher with DCS. ${ }^{10}$

Although a few studies have shown the superiority of DCS, it is still necessary to compare the two types of snares under the same conditions, including lesion size or location. This in vivo animal study was designed to evaluate the effectiveness and safety of the DCS for CSP compared to the TS.

\section{MATERIALS AND METHODS}

This study was approved by the Institutional Animal Care and Use Committee of KNOTUS (Registration number: 19KE-121 [2/6/2019]) and was performed in the National Center of Efficacy Evaluation for the Development of Health Products Targeting Digestive Disorders (NCEED; Incheon, Korea). Two replicates of animal experiments were conducted at a 6-month interval. A mini-pig (Sus scrofa) weighing approximately $30 \mathrm{~kg}$ was used for each experiment.

\section{Preparation before polypectomy}

Bowel preparation consisted of a clear fluid diet and $4 \mathrm{~L}$ of polyethylene glycol solution with ascorbic acid divided into four doses over 48 hours. The solution was administered via an orogastric gavage tube. The sedative consisted of zolazepam and tiletamine (Zoletil ${ }^{\circledR}$; Virbak, Peakhurst, Australia) $2.2 \mathrm{mg} /$ $\mathrm{kg}$, and xylazine (Rompun ${ }^{\circledR}$; Ilium, Smithfield, Australia) 1.1 $\mathrm{mg} / \mathrm{kg}$ injected intramuscularly. After endotracheal intubation, general inhalation anesthesia was maintained using $1 \%$ isoflurane (Ifran ${ }^{\circledR}$; Hana Pharm Co., Ltd., Seoul, Korea), and oxygen mixture. The mini-pig was laid in the left lateral position during the procedure.

\section{Polypectomy protocol}

All procedures were performed by a highly experienced endoscopist (HHL) using a high-resolution gastroscope with a 3.2-mm diameter working channel (GIF-Q260J; Olympus Co., Tokyo, Japan). A transparent cap (Disposable Distal Attachment, Model D-201-11304; Olympus) with an outer diameter of $11.8 \mathrm{~mm}$ was placed on the tip of the endoscope. Diminutive $(5 \mathrm{~mm})$ or small $(9 \mathrm{~mm})$ pseudolesions were demarcated using the snare tip and coagulation current (forced coagulation, effect 2, $40 \mathrm{~W}$, ICC-200; Erbe Elektromedizin $\mathrm{GmbH}$, Tübingen, Germany) (Fig. 1). The size of each pseudolesion was estimated by comparing it with the inner diameter of the

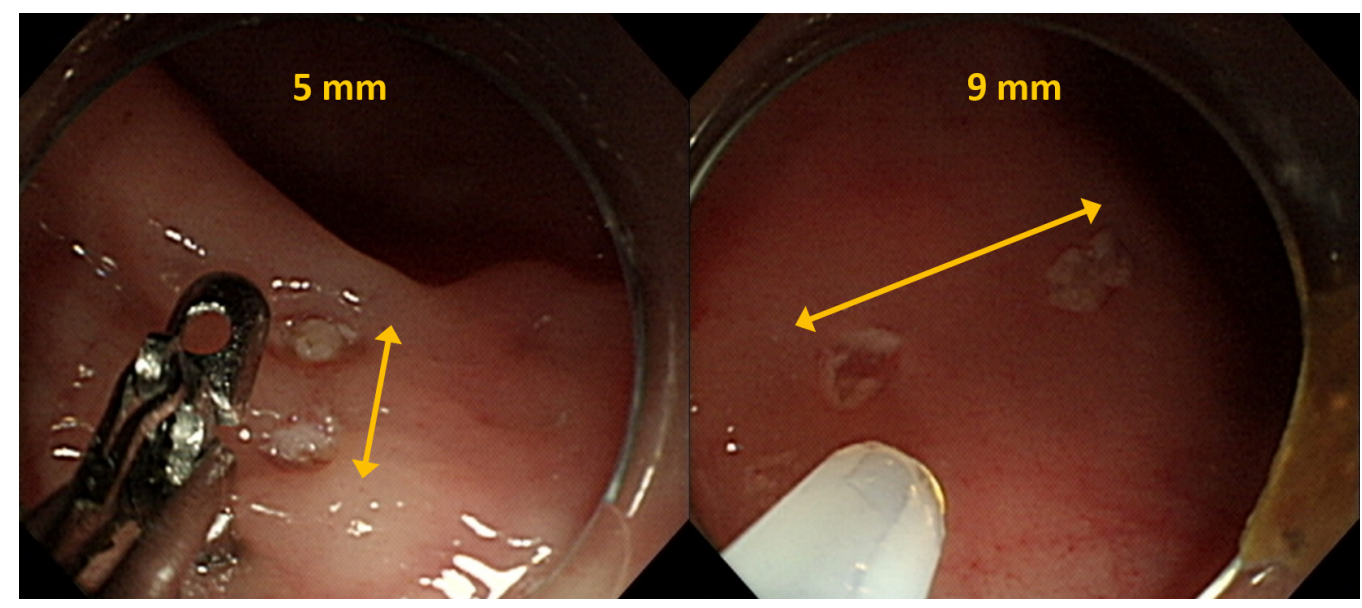

Fig. 1. Creating two sizes $(5 \mathrm{~mm}$ and $9 \mathrm{~mm}$ ) of pseudolesions by electrocoagulation using a snare tip. 

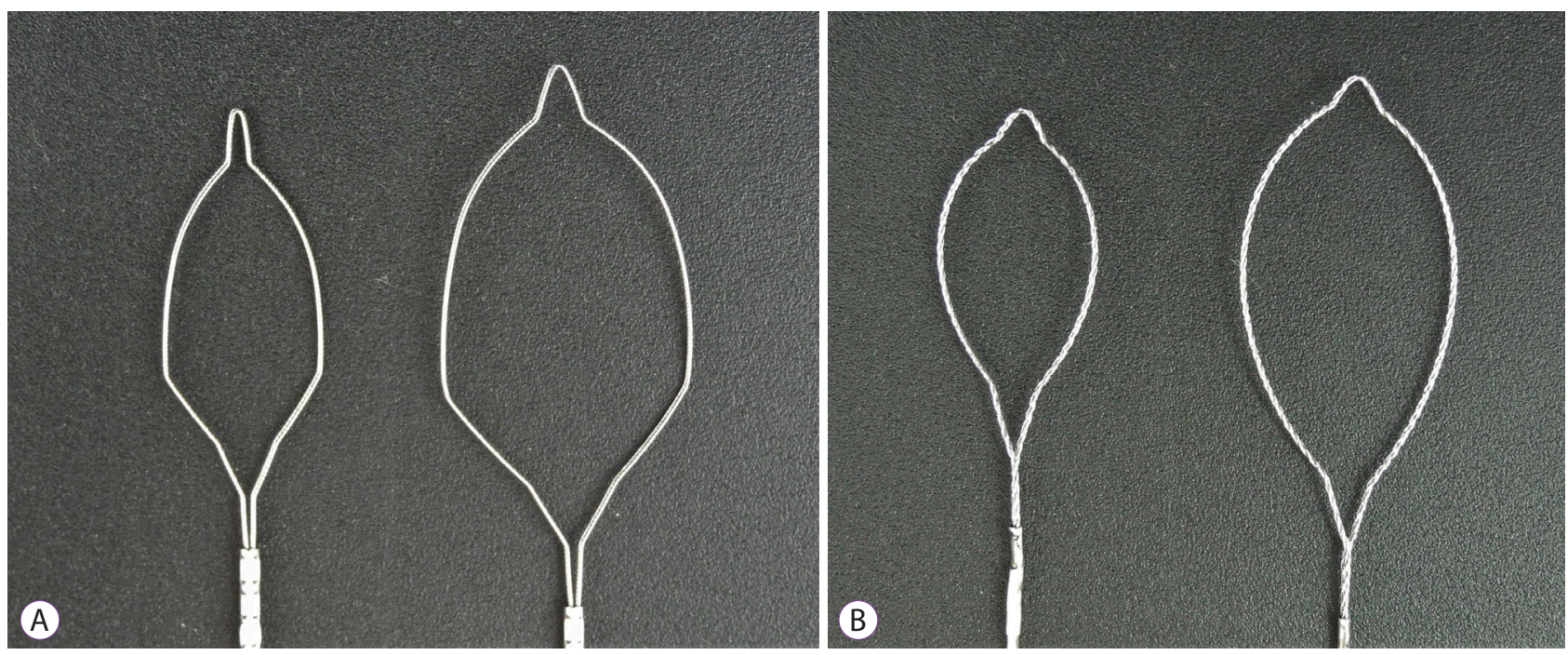

Fig. 2. (A) Dedicated cold snare (Optimos Polypectomy Snare Cold Type; Taewoong, Gimpo, Korea). Left, $10 \mathrm{~mm}$. Right, $15 \mathrm{~mm}$. (B) Traditional snare (Optimos Polypectomy Snare Oval Type; Taewoong). Left, $10 \mathrm{~mm}$. Right, $15 \mathrm{~mm}$.

distal attachment $(9.8 \mathrm{~mm})$. The pseudolesions were prepared at the colon 5-50 cm from the anal verge. For testing DCS and TS under the same conditions, a pair of pseudolesions of the same size were arranged side by side along the transverse axis of the colon at the same distance from the anus.

The DCS (Optimos Polypectomy Snare Cold Type; Taewoong, Gimpo, Korea) is shaped like a shield, and the diameter of the wire is $0.36 \mathrm{~mm}$ (Fig. 2A). Its shape and thin wire are appropriate for cold snaring. This snare was designed to be able to use electrosurgical currents for HSP. The TS (Optimos Polypectomy Snare Oval Type; Taewoong) is oval, and the diameter of the wire is $0.45 \mathrm{~mm}$ (Fig. 2B). A $10 \mathrm{~mm}$ DCS or TS was chosen for diminutive pseudolesions while a $15 \mathrm{~mm}$ DCS or TS was used for small pseudolesions.

The CSP technique was standardized during the procedure. ${ }^{11}$ After the snare was opened, the tip was anchored several millimeters distal to the polyp by gently pushing the catheter while keeping it down and right. Assuring that a 2 to $3 \mathrm{~mm}$ margin of normal tissue surrounded the pseudolesion, the snare wire was closed continuously until the lesion was guillotined. The ensnared polyp was not lifted nor tented during snare closure.

Snare stall was defined as failure of tissue amputation despite the first complete closure of the snare handle. If snare stall occurred, the "reopen and closure" technique was tried 2-3 times. The "reopen and closure" technique was performed as follows: the snare was reopened partially, gently lifted away from the colonic wall to release the excessively entrapped submucosal tissue and closed again. Technical success was defined as complete amputation of the ensnared tissue by CSP including following "reopen and closure". Complete resection was defined when the demarcations of the pseudolesions were completely removed by CSP. The resection margin of the polypectomy site was observed carefully to assess the quality of excision. The procedure time was calculated from the deployment of the snare to complete transection. Immediate bleeding was defined as spurting or oozing that continued for more than $30 \mathrm{sec}$.

\section{Outcome variables}

The primary outcome was the completeness of the procedure including the technical success rate and complete resection rate. The secondary outcomes were procedure duration, incidence of snare stall, uneven resection margin of polypectomy site, and adverse events such as immediate bleeding, perforation, and retrieval failure.

\section{Statistical analysis}

All continuous variables were expressed as mean ( \pm standard deviation) and were compared using the Student $t$-test or Mann-Whitney $U$ test as appropriate. Categorical variables were expressed as percentages and compared between groups using Chi-square or Fisher's exact test as appropriate. Variables with $p$-values $<0.05$ by univariate analysis were included in a multivariate logistic regression model to identify the predictive factors associated with complete resection. All analyses were performed with the aid of SAS software version 9.4 (SAS Institute, Cary, NC, USA). 


\section{RESULTS}

A total of 72 polypectomies were conducted for 36 diminutive and 36 small lesions (Supplementary Video 1).

In diminutive lesions, although the DCS group showed higher technical success $(94.4 \%$ [17/18] vs. $72.2 \%$ [13/18], $p=0.177)$ and complete resection rate $(94.1 \%$ [16/17] vs. $69.2 \%$ [9/13], $p=0.187$ ) as well as a shorter procedure time ( $37.0 \mathrm{sec}$ vs. $49.0 \mathrm{sec}, p=0.072$ ) compared to the TS group, these differences were not statistically significant. However, snare stalls and uneven resection margins occurred more frequently in the TS group compared with the DCS group (88.9\% [16/18] vs. $16.7 \%$ [3/18], $p<0.001$, and $46.2 \%$ [6/13] vs. $0.0 \%$ [0/17], $p=0.008$, respectively).

In small lesions, the DCS group showed higher technical success $(100.0 \%$ [18/18] vs. $55.6 \%$ [10/18], $p=0.003)$ and complete resection rate $(94.4 \%$ [17/18] vs. $40.0 \%$ [4/10], $p=0.006)$ as well as a shorter procedure duration $(28.5 \mathrm{sec}$ vs. $66.0 \mathrm{sec}$, $p=0.006)$ compared with the TS group. In addition, snare stalls and uneven resection margins occurred more frequently in the TS group compared with the DCS group (100.0\% [18/18] vs. $33.3 \%$ [6/18], $p<0.001$ and $100.0 \%$ [10/10] vs. $11.1 \%$ $[2 / 18], p<0.001$, respectively) (Supplementary Video 2, Fig. 3). With regard to adverse events, perforation occurred using both the $10 \mathrm{~mm}$ and $15 \mathrm{~mm}$ snares in the DCS group (Supplementary Video 3). Immediate bleeding and retrieval failure were not different between the two groups (Table 1).

In multivariate analysis, DCS was the only independent factor associated with complete resection (odds ratio, 15.09; 95\% confidence interval, 3.02-127.11) (Table 2).
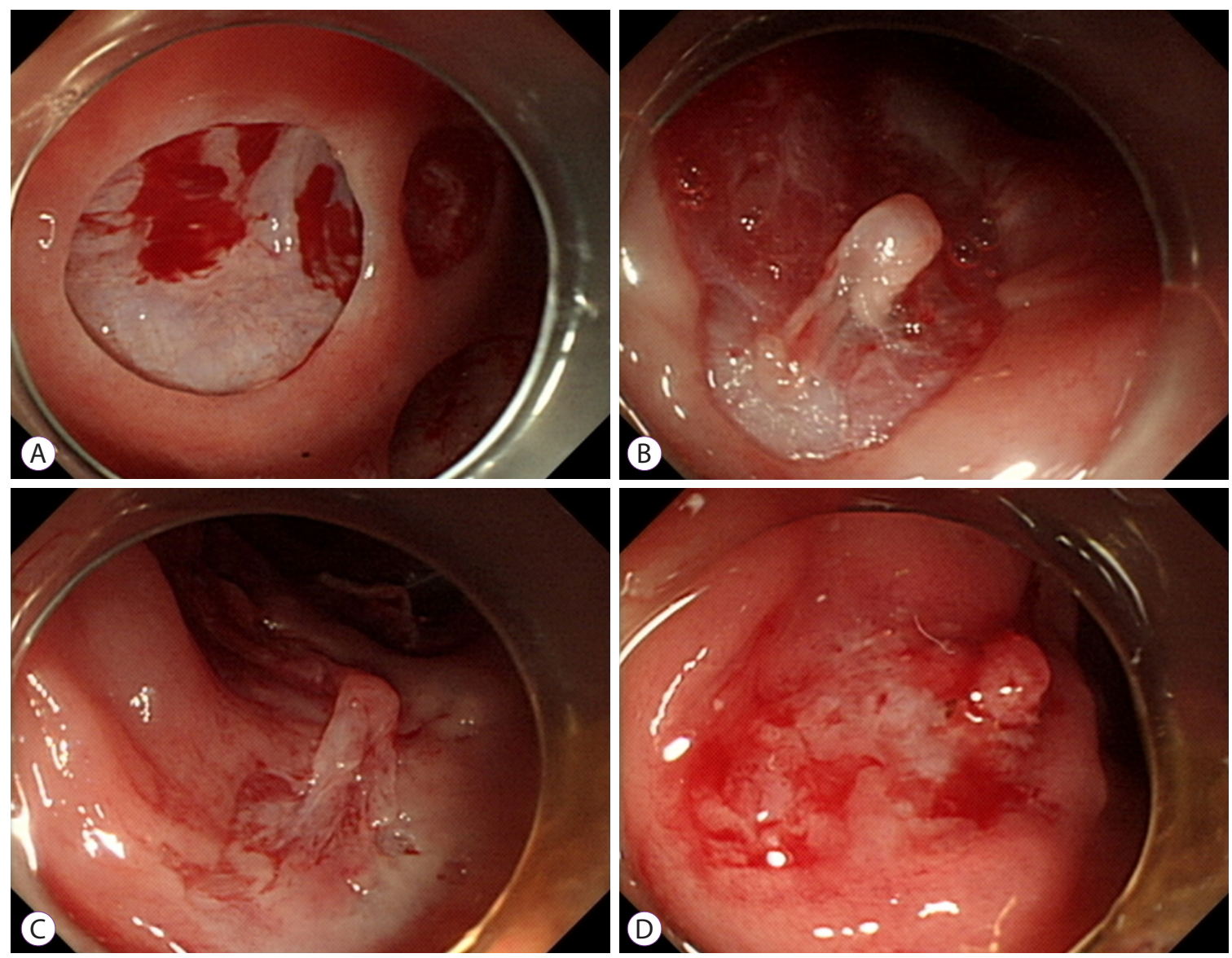

Fig. 3. Resection margins of cold snare polypectomy according to snare type and size. (A) Dedicated cold snare, $10 \mathrm{~mm}$. (B) Dedicated cold snare, $15 \mathrm{~mm}$. (C) Traditional snare, $10 \mathrm{~mm}$. (D) Traditional snare, $15 \mathrm{~mm}$. 
Table 1. Baseline Characteristics of the Study Population

\begin{tabular}{|c|c|c|c|c|c|c|}
\hline Lesion size & $5 \mathrm{mn}$ & & & $9 \mathrm{mn}$ & & \\
\hline Snare type & $\begin{array}{l}\text { Dedicated cold snare } \\
\qquad 10 \mathrm{~mm}(n=18)\end{array}$ & $\begin{array}{l}\text { Traditional snare } \\
10 \mathrm{~mm}(n=18)\end{array}$ & $p$-value & $\begin{array}{l}\text { Dedicated cold snare } \\
\qquad 15 \mathrm{~mm}(n=18)\end{array}$ & $\begin{array}{c}\text { Traditional snare } \\
15 \mathrm{~mm}(n=18)\end{array}$ & $p$-value \\
\hline Location (cm from anus) (range) & $16.0(13-30)$ & $17.0(13-28)$ & 0.949 & $22.5(11-29)$ & $24.0(12-31)$ & 0.763 \\
\hline Technical success, $\%$ & $94.4(17 / 18)$ & $72.2(13 / 18)$ & 0.177 & $100(18 / 18)$ & $55.6(10 / 18)$ & 0.003 \\
\hline Time of procedure, sec (range) & $37.0(28-55)$ & $49.0(43-60)$ & 0.072 & $28.5(23-55)$ & $66.0(47-75)$ & 0.006 \\
\hline Snare stall, \% & $16.7(3 / 18)$ & $88.9(16 / 18)$ & $<0.001$ & $33.3(6 / 18)$ & $100(18 / 18)$ & $<0.001$ \\
\hline Uneven resection margin, $\%$ & $0.0(0 / 18)$ & $46.2(6 / 13)$ & 0.008 & $11.1(2 / 18)$ & $100(10 / 10)$ & $<0.001$ \\
\hline Complete resection, $\%$ & $94.1(16 / 17)$ & $69.2(9 / 13)$ & 0.187 & $94.4(17 / 18)$ & $40.0(4 / 10)$ & 0.006 \\
\hline Size of resected mucosa, mm & $7.6 \pm 1.5$ & $7.5 \pm 2.3$ & 0.874 & $12.0 \pm 1.8$ & $8.5 \pm 2.2$ & 0.014 \\
\hline Immediate bleeding, \% & $0.0(0 / 17)$ & $7.7(1 / 13)$ & 0.891 & $5.6(1 / 18)$ & $20.0(2 / 10)$ & 0.585 \\
\hline Perforation & $5.9(1 / 17)$ & $0.0(0 / 13)$ & $>0.999$ & $5.6(1 / 18)$ & $0.0(0 / 10)$ & $>0.999$ \\
\hline Retrieval failure & $5.9(1 / 17)$ & $7.7(1 / 13)$ & $>0.999$ & $5.6(1 / 18)$ & $0.0(0 / 10)$ & $>0.999$ \\
\hline
\end{tabular}

Table 2. Multivariate Logistic Regression Analysis for Complete Resection

\begin{tabular}{|c|c|c|c|c|c|c|}
\hline & \multicolumn{3}{|c|}{ Univariate } & \multicolumn{3}{|c|}{ Multivariate } \\
\hline & OR & $95 \% \mathrm{CI}$ & $p$-value & OR & $95 \% \mathrm{CI}$ & $p$-value \\
\hline Location (cm from anus) & 0.94 & $0.89-0.99$ & 0.020 & 0.93 & $0.87-0.99$ & 0.028 \\
\hline Lesion size & & & 0.750 & & & \\
\hline $5 \mathrm{~mm}$ & 1 & Reference & & & & \\
\hline $9 \mathrm{~mm}$ & 0.90 & $0.69-1.17$ & 0.436 & & & \\
\hline \multicolumn{7}{|l|}{ Snare type } \\
\hline Traditional snare & 1 & Reference & & & & \\
\hline Dedicated cold snare & 12.69 & $2.87-90.34$ & 0.003 & 15.09 & $3.02-127.11$ & 0.003 \\
\hline
\end{tabular}

$\mathrm{CI}$, confidence interval; $\mathrm{OR}$, odds ratio.

\section{DISCUSSION}

This in vivo animal study demonstrated that a DCS was more effective in terms of technical success and complete resection than a TS when performing CSP. Especially, the effectiveness of the DCS was more evident for small pseudolesions than it was for diminutive lesions. In addition, the procedure duration for CSP using the DCS was reduced compared with the TS.

A snare designed exclusively for cold resection has recently been introduced. ${ }^{7}$ The design of this DCS includes a thinner wire and a shield-shaped loop, rather than the oval loop of a TS. The DCS used in our study also had this design. The decreased diameter of the DCS increases the pressure applied to the mucosal surface per unit area and can be helpful to decrease the incidence of technical failures, and uneven resection. In addition, the shield-shaped loop is closed gradually from the distal to the proximal side during ensnaring whereas the oval loop is closed from all directions. Consequently, the mucosa can be more easily pinched by the DCS compared with the TS.

The present study confirmed that cold polypectomy with a DCS is more effective than a thick-wired oval TS. For all of the lesions, regardless of size, all but one pseudolesion (35/36) were successfully resected using a DCS. Furthermore, the mean time spent in polypectomies was shorter using the DCS compared with the TS.

The differences between the two types of snares became more prominent when the lesion size increased. As the size of the lesion is increased, the contact area between the snare and 
the ensnared tissue also increased, and the pressure per unit area of the mucosal surface decreased. This caused snare stall, which resulted in polypectomy failure even after using the "reopen and closure" technique. According to our results, snare stall occurred more frequently in the TS group. In particular, we experienced snare stall in all the small lesions in the TS group, and technical success could be achieved in only about half of them. This result is in line with a previous human study that demonstrated that the endoscopic completeness of the excision rate was significantly higher with the DCS, and that resection failures occurred only with a TS. ${ }^{9}$ Endoscopic complete resection inevitably leads to a histological complete resection rate. Horiuchi et al. reported that the difference in histological complete resection rate was greatest for $8-10 \mathrm{~mm}$ polyps between the two types of snares. ${ }^{10}$ A network meta-analysis comparing cold polypectomy techniques for diminutive colorectal polyps also revealed that a DCS was superior to a TS in terms of histological complete resection. ${ }^{12}$

The incidence of adverse events in terms of immediate bleeding and retrieval failure were very low and were comparable in both groups. These results correspond well with those of earlier studies, which reported no statistically significant differences in adverse events related to CSP between the two types of snares. ${ }^{9,10,13}$ Regardless of the snare type, previous studies suggested that CSP was sufficiently safe. ${ }^{4,14,15}$ However, we experienced unexpected perforations in the DCS group. Although there were no perforations after CSP in recent meta-analyses that included a large number of CSP cases in human studies, ${ }^{4,14,15}$ a recent report presented two cases of perforation with CSP that were successfully treated by endoscopic clipping. It is unclear why two cases of perforations occurred in the DCS group. First, the pressure against the colonic wall during ensnaring in our in vivo study might be much stronger compared with that during daily clinical practice, since we had to capture the completely flat pseudolesions. Second, since the pig colon is generally longer, but thinner than the human colon, it is more likely to capture not only the mucosal and submucosal layers, but also the muscularis propria during snaring. ${ }^{16}$

We expect the use of the DCS will increase gradually. The earlier model of the DCS was not designed for combined use with electrosurgical currents, a so-called HSP. ${ }^{7,10}$ However, the recent models, as well as the snare used in the present study, were made to be able to be used with electrocautery. Therefore, since it could be used for both cold and hot snares, there is no need to change to a TS even if we find a large polyp that requires HSP.

In conclusion, use of the DCS for CSP increases the technical success rate and complete resection rate, and decreases the procedure duration. Despite its well-known safety, CSP may also be associated with perforation. Use of the DCS is recommended with priority for CSP of lesions $>5 \mathrm{~mm}$.

Conflicts of Interest

Han Hee Lee and Bo-In Lee are a stockholder in Omni Medical Co., the Catholic University of Korea Holdings.

Funding

This study was supported by a grant from the Korean Gastrointestinal Endoscopy Research Foundation (2019 Investigation Grant).

Author Contributions

Conceptualization: Bo-In Lee

Data curation: Han Hee Lee

Formal analysis: HHL, BIL

Funding acquisition: BIL, Hoon Jai Chun, Ho Gak Kim

Investigation: $\mathrm{HHL}, \mathrm{BIL}$

Methodology: HHL, BIL

Project administration: HHL, BIL, Jung-Wook Kim, Hyun Lim, Si Hyung Lee

Resources: Jun-Hyung Cho, Yunho Jung, Kyoung Oh Kim, Chan Gyoo Kim, Kee Myung Lee

Supervision: Jong-Jae Park, Myung-Gyu Choi, HJC, HGK

Visualization: HHL, BIL

Writing-original draft: HHL

Writing-review\&editing: BIL

ORCID

Han Hee Lee:

Bo-In Lee:

Jung-Wook Kim:

Hyun Lim:

Si Hyung Lee:

Jun-Hyung Cho:

Yunho Jung:

Kyoung Oh Kim:

Chan Gyoo Kim:

Kee Myung Lee:

Jong-Jae Park:

Myung-Gyu Choi:

Hoon Jai Chun:

Ho Gak Kim:

https://orcid.org/0000-0002-8244-374X https://orcid.org/0000-0002-0218-4136 https://orcid.org/0000-0002-5383-7934 https://orcid.org/0000-0001-6581-6420 https://orcid.org/0000-0001-7221-7506 https://orcid.org/0000-0003-2075-2333 https://orcid.org/0000-0002-7760-0050 https://orcid.org/0000-0002-5365-2550 https://orcid.org/0000-0002-1651-2559 https://orcid.org/0000-0003-3785-693X https://orcid.org/0000-0002-4642-5405 https://orcid.org/0000-0003-4083-5187 https://orcid.org/0000-0002-5539-361X https://orcid.org/0000-0003-3365-1662

Supplementary Materials

Video 1 . The procedure process of cold snare polypectomy using a dedicated cold snare (https://doi.org/10.5946/ce.2020.096.v001).

Video 2. Video documentation of a snare stall and resection failure using cold snare polypectomy with a traditional snare (https://doi. org/10.5946/ce.2020.096.v002).

Video 3. Video documentation of a perforation case using cold snare polypectomy with a dedicated cold snare (https://doi.org/10.5946/ ce.2020.096.v003).

\section{REFERENCES}

1. Tappero G, Gaia E, De Giuli P, Martini S, Gubetta L, Emanuelli G. Cold snare excision of small colorectal polyps. Gastrointest Endosc 1992;38:310-313.

2. Lee CK, Shim JJ, Jang JY. Cold snare polypectomy vs. Cold forceps 
polypectomy using double-biopsy technique for removal of diminutive colorectal polyps: a prospective randomized study. Am J Gastroenterol 2013;108:1593-1600.

3. Kim JS, Lee BI, Choi H, et al. Cold snare polypectomy versus cold forceps polypectomy for diminutive and small colorectal polyps: a randomized controlled trial. Gastrointest Endosc 2015;81:741-747.

4. Shinozaki S, Kobayashi Y, Hayashi Y, Sakamoto H, Lefor AK, Yamamoto H. Efficacy and safety of cold versus hot snare polypectomy for resecting small colorectal polyps: systematic review and meta-analysis. Dig Endosc 2018;30:592-599.

5. Kawamura T, Takeuchi Y, Asai S, et al. A comparison of the resection rate for cold and hot snare polypectomy for 4-9 mm colorectal polyps: a multicentre randomised controlled trial (CRESCENT study). Gut 2018;67:1950-1957.

6. Ferlitsch M, Moss A, Hassan C, et al. Colorectal polypectomy and endoscopic mucosal resection (EMR): European Society of Gastrointestinal Endoscopy (ESGE) clinical guideline. Endoscopy 2017;49:270-297.

7. Repici A, Strangio G, Jovani M, et al. Efficacy and safety of a new polypectomy SNARE for cold-polypectomy of subcentimetric colorectal polyps: the E-Scope (efficacy and safety of cold polypectomy) trial. Gastrointest Endosc 2014;79(5 Suppl):AB542.

8. Horiuchi A, Ikuse T, Tanaka N. Cold snare polypectomy: indications, devices, techniques, outcomes and future. Dig Endosc 2019;31:372-377.
9. Din S, Ball AJ, Riley SA, Kitsanta P, Johal S. Cold snare polypectomy: does snare type influence outcomes? Dig Endosc 2015;27:603-608.

10. Horiuchi A, Hosoi K, Kajiyama M, Tanaka N, Sano K, Graham DY. Prospective, randomized comparison of 2 methods of cold snare polypectomy for small colorectal polyps. Gastrointest Endosc 2015;82:686-692.

11. Hewett DG. Cold snare polypectomy: optimizing technique and technology (with videos). Gastrointest Endosc 2015;82:693-696.

12. Jung YS, Park CH, Nam E, Eun CS, Park DI, Han DS. Comparative efficacy of cold polypectomy techniques for diminutive colorectal polyps: a systematic review and network meta-analysis. Surg Endosc 2018:32:1149-1159.

13. Dwyer JP, Tan JYC, Urquhart P, et al. A prospective comparison of cold snare polypectomy using traditional or dedicated cold snares for the resection of small sessile colorectal polyps. Endosc Int Open 2017;5:E1062-E1068.

14. Thoguluva Chandrasekar V, Spadaccini M, Aziz M, et al. Cold snare endoscopic resection of nonpedunculated colorectal polyps larger than $10 \mathrm{~mm}$ : a systematic review and pooled-analysis. Gastrointest Endosc 2019;89:929-936.e3.

15. Qu J, Jian H, Li L, et al. Effectiveness and safety of cold versus hot snare polypectomy: a meta-analysis. J Gastroenterol Hepatol 2019;34:49-58.

16. Mersmann HJ, Pond WG. Biology of the domestic pig. 2nd ed. Ithaca: Cornell University Press; 2001. 